(1)

CrossMark

\title{
Asthma and COVID-19: do we finally have answers?
}

\author{
Katrien Eger (1) and Elisabeth H. Bel
}

Affiliation: Dept of Respiratory Medicine, Amsterdam University Medical Center, University of Amsterdam, Amsterdam, The Netherlands.

Correspondence: Elisabeth Bel, Amsterdam UMC, University of Amsterdam, Dept of Respiratory Medicine F5152, Meibergdreef 9, 1105 AZ Amsterdam, The Netherlands. E-mail: e.h.beldamsterdamumc.nl

\section{@ERSpublications}

Large-scale studies confirm previous findings about a slightly increased incidence of COVID-19, but not of severe COVID-19, in asthma patients. Still, no definitive conclusions can be drawn since many bias factors have not been taken into account. https://bit.ly/34FRfmT

Cite this article as: Eger K, Bel EH. Asthma and COVID-19: do we finally have answers? Eur Respir J 2021; 57: 2004451 [https://doi.org/10.1183/13993003.04451-2020].

The coronavirus disease 2019 (COVID-19) pandemic has already claimed the lives of nearly 1.5 million people and the virus is continuing to spread across the world [1]. The disease can affect anyone, and although SARS-CoV-2 infection leads to mild COVID-19 in the majority of cases, the proportion of patients developing severe pneumonia is of great concern.

It is now well-recognised that older age, obesity, cardiovascular disease and diabetes are risk factors for poor COVID-19 outcome [2-4]. What is not yet clear is whether chronic respiratory diseases like asthma are amongst the risk factors as well. The many studies that have addressed this question show discrepant results and point towards numerous factors that may play a role in the susceptibility and severity of COVID-19 in asthma patients [5-10]. These include the severity of asthma itself, the asthma phenotype (allergic or non-allergic), asthma medication (corticosteroids or no corticosteroids), and comorbidities [11-15]. Because of this complex interplay between numerous factors involved, there is a need for large-scale studies that allow adjustment for confounders, making it possible to evaluate the true impact of asthma on the susceptibility and outcome of COVID-19.

This is exactly the approach taken by CHOI et al. [16] and IzQuierdo et al. [17] in the two real-life studies in this issue of the European Respiratory Journal. While CHог et al. [16] included all COVID-19 cases in Korea $(\mathrm{n}=7590)$ by using a national claims database, IzQUIERDo et al. [17] analysed medical record data from 71182 patients with asthma who attended medical services from a region in Spain. CHOI et al. [16] found a higher frequency of asthma in the COVID-19 population compared to the general population (2.9\% versus $1.6-2.2 \%)$, while IzQuierdo et al. [17] found a higher frequency of COVID-19 amongst asthma patients compared to the general population (1.41\% versus $0.86 \%)$. In addition, IzQUiERDo et al. [17] showed an even higher incidence of COVID-19 in patients on biologic therapy (2.31\%). Thus, both studies suggest that the susceptibility for contracting COVID-19 in asthma patients is higher than in the general population, especially in those with severe asthma on biologic therapy.

Regarding the severity of COVID-19, IzQUIERDo et al. [17] reported equal hospitalisation rates in asthma and non-asthma patients with COVID-19 (in both cases 26\%). Likewise, CHOI et al. [16] found that COVID-19 severity as illustrated by ICU admission rate and duration were similar between COVID-19 patients with and without asthma. Although mortality rates were higher in patients with asthma, asthma 
and asthma severity did not show to be significant predictors of COVID-19 related mortality after adjustment for age, sex and comorbidities. A higher prevalence of inhaled corticosteroid (ICS) users in patients who were hospitalised for COVID-19 was found by IZQUIERDo et al. [17], but CHOI et al. [16] did not find any association between asthma medications and COVID-19 outcome.

The studies by CHOI et al. [16] and IzQuiERdo et al. [17] are both unique and important because of their impressive sample size and innovative approach (big data analytics and artificial intelligence in the study by IzQUIERDo et al. [17]). But have these large-scale studies provided us with definitive answers as to whether asthma, the severity of asthma and asthma medications affect COVID-19 susceptibility and severity? The higher incidence of COVID-19 among asthma patients reported in both studies is more or less consistent with other large (but smaller) studies [8, 18-20]. However, there are still some outstanding issues that may have influenced the results. First, the method by which asthma was diagnosed was very strict in the study by СHоI et al. [16] and rather vague in the study by IzQuierdo et al. [17], possibly leading to under- or over-diagnosis, respectively. This may also explain differences in proportions of patients using ICS between the two studies (23\% versus 41\%). Another bias factor may have been the methods by which COVID-19 was diagnosed. CHOI et al. [16] exclusively included PCR-confirmed COVID-19 cases, while IzQUIERDo et al. [17] also included patients with suspected COVID-19 based on clinical parameters. In addition, infection rates may also have been affected by testing policies or shielding advice, for example, if older patients, patients with comorbidities such as asthma, or patients with more severe symptoms, tested more frequently or better protected themselves. Thus, with such inaccuracies in case definition and variations in local conditions, it remains difficult to determine with certainty whether asthma patients are more susceptible to getting COVID-19 or not.

How about the risk of poor outcome or death from COVID-19? Severity and outcome of COVID-19 are highly dependent on age, as children experience less severe COVID-19 than elderly people [21]. Age is therefore an important confounder in the assessment of risk of contracting severe COVID-19. IZQUIERDO et al. [17] showed that asthma patients without COVID-19 were younger and more likely to have eczema and rhinitis, while those with COVID-19 were older and more likely to have comorbidities like hypertension and diabetes. These results could very well be confounded by age. CHOI et al. [16] solved this issue by adjusting for age and comorbidities in a multivariate analysis, which would have been of additive value in the study by IzQuierdo et al. [17].

What do the two studies teach us about safety of asthma medication, in particular ICS with respect to COVID-19 susceptibility and outcome? There is much debate about the risk-increasing or protective effects of asthma medication in the course of COVID-19 disease [22]. In such risk assessment, asthma severity and phenotype are important confounders. CHOI et al. [16] found higher healthcare-related costs

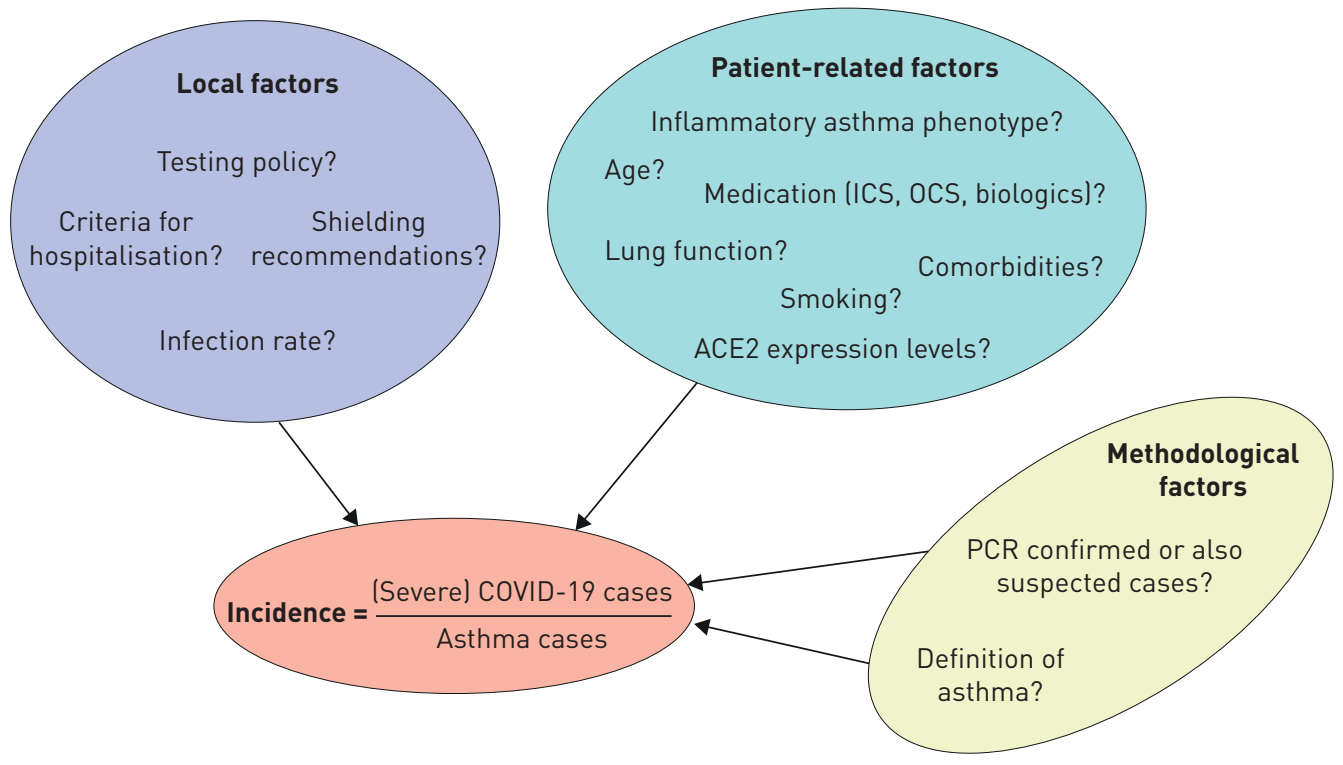

FIGURE 1 Factors that may influence reported incidences of (severe) coronavirus disease 2019 (COVID-19) in asthma patients. The reported incidences of (severe) COVID-19 cases among asthma patients are not determined by patient-related factors alone. Also, local factors and the applied methodologies can play an important role. ACE2: angiotensin converting enzyme 2; ICS: inhaled corticosteroids; OCS: oral corticosteroids. 
in patients using oral short-acting $\beta$-agonists (SABA). However, less than $4 \%$ of patients used oral SABA in the 2 months before COVID-19 diagnosis, suggesting that not oral SABA itself, but other factors, such as the type of patients that are prescribed oral SABA, played a role in these increased costs. Not surprisingly, regression analysis showed that asthma medications were not independently associated with poor outcome of COVID-19. CHOI et al. [16] also found a longer hospital stay in patients on Step 5 treatment (defined as $\geqslant 90$ days oral corticosteroids in the previous year), but firm conclusions cannot be drawn as only four patients were on Step 5 treatment. IZQUIERDo et al. [17] conclude that ICS use is "safe", because ICS users in their study were less frequently hospitalised for COVID-19 than non-ICS users. This finding is, however, in contrast with a recent observational study in the UK showing an association between higher ICS doses and risk of COVID-19 related death in asthma patients [13]. The studies by CHor et al. [16] and IzQuierdo et al. [17] did not take dosage of ICS into account, which may partly explain the discrepancy between the three studies regarding the influence of ICS use on COVID-19 outcome.

What about the use of asthma biologics and the risk of COVID-19? Currently available asthma biologics block pathways of type 2 inflammation. This type of inflammation, in particular allergic inflammation, has been suggested to have a protective effect through down-regulating the angiotensin converting enzyme (ACE) 2 receptor used by the virus to enter host cells, or hypothetically, by counterbalancing the exaggerated anti-viral immune response observed in severe COVID-19 patients [23, 24]. IzQUIERDO et al. [17] analysed a large number of patients on biologic therapy $(n=865)$, and found a relatively high incidence of COVID-19 of $2.3 \%$ in these patients, while this was $1.4 \%$ in the general asthma population. Only two out of 20 infected patients on asthma biologics (10\%) were hospitalised. While these numbers are small, they are consistent with other reports suggesting that there is no increased risk of a poor outcome in asthma patients on biologics $[25,26]$.

In summary, these large-scale studies have confirmed previous findings about the risk for asthma patients to develop (severe) COVID-19. Asthma patients appear to be slightly more susceptible to contracting COVID-19, but severe disease progression does not seem to be related to medication use, including asthma biologics, but rather to older age and comorbidities.

However, no definitive conclusions can be drawn yet as many factors can influence the reported incidences of (severe) COVID-19 (figure 1). These potential bias factors have not been taken into account in the published studies so far and therefore many questions remain unanswered. Similar large-scale, preferably multinational real-life studies with detailed information on asthma phenotype and medication usage in patients with a confirmed diagnosis of COVID-19 would be an ideal next step to further build on this new evidence.

Conflict of interest: K. Eger has nothing to disclose. E.H. Bel reports grants and personal fees from AstraZeneca, GSK, Novartis and Teva, personal fees from Sanofi/Regeneron, Sterna and Chiesi, outside the submitted work.

\section{References}

1 World Health Organization. Weekly Epidemiological Update. www.who.int/publications/m/item/weekly-epidemiologicalupdate---1-december-2020 Date last updated: 1 Dec 2020. Date last accessed: 3 Dec 2020.

2 Wu Z, McGoogan JM. Characteristics of and important lessons from the coronavirus disease 2019 (COVID-19) outbreak in China: summary of a report of 72314 cases from the Chinese Center for Disease Control and Prevention. JAMA 2020; 323: 1239-1242.

3 Guan W-J, Liang W-H, Zhao Y, et al. Comorbidity and its impact on 1590 patients with COVID-19 in China: a nationwide analysis. Eur Respir J 2020; 55: 2000547.

4 Garg S, Kim L, Whitaker M, et al. Hospitalization rates and characteristics of patients hospitalized with laboratory-confirmed coronavirus disease 2019 - COVID-NET, 14 States, March 1-30, 2020. MMWR Morb Mortal Wkly Rep 2020; 69: 458-464.

5 Choi H-G, Wee JH, Kim SY, et al. Association between asthma and clinical mortality/morbidity in COVID-19 patients using clinical epidemiologic data from Korean Disease Control \& Prevention. Allergy 2020; in press [https://doi.org/10.1111/all.14675].

6 Zhu Z, Hasegawa K, Ma B, et al. Association of asthma and its genetic predisposition with the risk of severe COVID-19. J Allergy Clin Immunol 2020; 146: 327-329.e4.

7 Green I, Merzon E, Vinker S, et al. COVID-19 susceptibility in bronchial asthma. J Allergy Clin Immunol Pract 2020; in press [https://doi.org/10.1016/j.jaip.2020.11.020].

8 Mahdavinia M, Foster KJ, Jauregui E, et al. Asthma prolongs intubation in COVID-19. J Allergy Clin Immunol Pract 2020; 8: 2388-2391.

9 Lieberman-Cribbin W, Rapp J, Alpert N, et al. The impact of asthma on mortality in patients with COVID-19. Chest 2020; 194: 2019-2020.

10 Avdeev S, Moiseev S, Brovko M, et al. Low prevalence of bronchial asthma and chronic obstructive lung disease among intensive care unit patients with COVID-19. Allergy 2020; 75: 2703-2704.

11 Yang JM, Koh HY, Moon SY, et al. Allergic disorders and susceptibility to and severity of COVID-19: a nationwide cohort study. J Allergy Clin Immunol 2020; 146: 790-798. 
12 Beurnier A, Jutant E-M, Jevnikar M, et al. Characteristics and outcomes of asthmatic patients with COVID-19 pneumonia who require hospitalisation. Eur Respir J 2020; 56: 2001875.

13 Schultze A, Walker AJ, MacKenna B, et al. Risk of COVID-19-related death among patients with chronic obstructive pulmonary disease or asthma prescribed inhaled corticosteroids: an observational cohort study using the OpenSAFELY platform. Lancet Respir Med 2020; 8: 1106-1120.

14 Peters MC, Sajuthi S, Deford P, et al. COVID-19 related genes in sputum cells in asthma: relationship to demographic features and corticosteroids. Am J Respir Crit Care Med 2020; 202: 83-90.

15 Camiolo M, Gauthier M, Kaminski N, et al. Expression of SARS-CoV-2 receptor ACE2 and coincident host response signature varies by asthma inflammatory phenotype. J Allergy Clin Immunol 2020; 146: 315-324.e7.

16 Choi YJ, Park J-Y, Lee HS, et al. Effect of asthma and asthma medication on the prognosis of patients with COVID-19. Eur Respir J 2021; 57: 2002226.

17 Izquierdo JL, Almonacid C, González Y, et al. The impact of COVID-19 on patients with asthma. Eur Respir J 2021; 57: 2003142

18 Lovinsky-Desir S, Deshpande DR, De A, et al. Asthma among hospitalized patients with COVID-19 and related outcomes. J Allergy Clin Immunol 2020; 146: 1027-1034.e4.

19 Cchiba KD, Patel GB, Vu THT, et al. Prevalence and characterization of asthma in hospitalized and non-hospitalized patients with COVID-19. J Allergy Clin Immunol 2020; 146: 307-314.e4.

20 Wang L, Foer D, Bates WD, et al. Risk factors for hospitalization, intensive care, and mortality among patients with asthma and COVID-19. J Allergy Clin Immunol 2020; 146: 808-812.

21 Götzinger F, Santiago-García B, Noguera-Julián A, et al. COVID-19 in children and adolescents in Europe: a multinational, multicentre cohort study. Lancet Child Adolesc Health 2020; 4: 653-661.

22 Halpin DMG, Singh D, Hadfield RM. Inhaled corticosteroids and COVID-19: a systematic review and clinical perspective. Eur Respir J 2020; 55: 2001009.

23 Jackson DJ, Busse WW, Bacharier LB, et al. Association of respiratory allergy, asthma and expression of the SARS-CoV-2 receptor, ACE2. J Allergy Clin Immunol 2020; 146: 203-206.e3.

24 Carli G, Cecchi L, Stebbing J, et al. Is asthma protective against COVID-19. Allergy 2020; in press [https://doi.org/ 10.1111/all.14426].

25 Hanon S, Brusselle G, Deschampheleire M, et al. COVID-19 and biologics in severe asthma: data from the Belgian Severe Asthma Registry. Eur Respir J 2020; 56: 2002857.

26 Heffler E, Detoraki A, Contoli M, et al. COVID-19 in Severe Asthma Network in Italy (SANI) patients: clinical features, impact of comorbidities and treatments. Allergy 2020; in press [https://doi.org/10.1111/all.14532]. 